\title{
PENGARUH BUDAYA ORGANISASI, LINGKUNGAN KERJA, TERHADAP KINERJA DOSEN DAN KEPUASAN KERJA SEBAGAI VARIABEL INTERVENING PADA UNIVERSITAS SATYA NEGARA INDONESIA (USNI)
}

\author{
Guston Sitorus
}

Dosen Tetap Program S1 Jurusan Manajemen Fakultas Ekonomi Universitas Satya Negara Indonesia mkb_guston01@yahoo.com

\begin{abstract}
The objective of this research is to anlize and test the effect of organizational cultural, work enviroment, and job satisfaction on performance. Performance is assumed to be significantly effected by the organizational cultural, work enviroment, and job satisfaction that pertain in the organization. The causal study reported here aimed to examine the hypothesis. It was conducted through a survey in the Satya Negara Indonesia University a sample of 50 lecturer from the overall population of 50 lecturer employe. The data of each variable were collected separately by the respondens' filling in a questionnaire. The path technique was applied to analyze the data wich had been previously treated with the aggressive and coorelation procedure. The result proved that the employee performance was directly effected by the organizational cultural, the work envoroment, and job satisfaction was in turn, directly effected by organizational cultural and work enviroment. The findings suggest that the variation of performance of the lecturer might have been effected by the organizational cultural, the work enviroment, and the job satisfaction in the organization. This further implies the need take the variables of organizational cultural, job satisfaction, and performance into the consideration in the strategic planning of the human resources development in the Satya Negara Indonesia University
\end{abstract}

Key words : Organizational Cultural, Work Enviroment, Job Satisfaction, and Performance.

\section{Pendahuluan (Introduction)}

Di era kepimpinan Presiden Jokowi ini diawali dengan penekanan pada pembangunan manusia yang berkualitas dan bermoral dengan membuat gerakan revolusi mental. Revolusi mental ini akan tercipta dengan memperbaiki sistem pendidikan nasional mulai dari Sekolah Dasar sampai dengan Perguruan Tinggi. Dengan demikian semua pendidikan formal akan berkonstribusi positif dalam menciptakan manusia yang cerdas, terampil, professional, dan bermoral.

Perguruan tinggi sebagai lembaga pendidikan terakhir dalam menciptakan tenaga-tenaga yang professional tentunya harus benar-benar memperhatikan proses belajar mengajar sehingga lulusannya benar-benar sesuai dengan yang diharapkan. Proses belajar mengajar yang berkualitas menjadi tanggungjawab seorang Dosen, sehingga kualitas dosen menjadi sangat penting atau dosen menjadi pusat perhatian pihak manajemen kampus.

Pengelolaan Dosen yang semakin profesional akan sangat dibutuhkan agar para dosen semakin giat meningkatkan kemapuannya dan melaksankan tugas-tugasnya dengan baik sehingga kinernjanya semakin meningkat. Dosen akan semakin giat melaksanakan tugas-tugas Tridarma Perguruan Tinggi dengan penuh dedikasi secara teratur setiap semester tentunya dengan dukungan dari berbagai pihak terutama pihak manajemen sehingga kinerja dosen sangat memuaskan.

Pengelolaan sumber daya manusia yang profesional ini dapat dilakukan dengan melaksanakan fungsi-fungsi manajemen sumber daya manusia dengan baik. Sumber daya 
manusia adalah subyek dan obyek dalam pencapaian tujuan organisasi. Sumber daya manusia di dalam organisasi harus dikelola dengan sebaik-baiknya agar terbentuk sumber daya manusia yang berkualitas. Peningkatan kualitas sumber daya dan juga berbagai factor lain menjadi pokok perhatian pihak manajemen sehingga kinerja pegawai meningkat, seperti budaya organisasi, lingkungan kerja, kepuasan pegawai, dan sebagainya.

Budaya organisasi merupakan nilai-nilai dan kebiasaan yang diterima sebagai acuan bersama yang diikuti dan dihormati di dalam suatu organisasi, kebiasaan ini menjadi budaya kerja sumber daya manusia di dalam organisasi yang sering dinamakan budaya organisasi, budaya organisasi yang kuat memberikan kepada karyawan pemahaman yang jelas tentang cara penyelesaian urusan organisasi. Robbin (2006:721) mendefinisikan budaya organisasi adalah sistem makna bersama yang dianut oleh anggota-anggota yang membedakan organisasi itu dari organisasi-organisasi yang lain. Sistem makna bersama ini, bila diamati dengan lebih seksama merupakan seperangkat karakteristik utama yang di hargai oleh organisasi.

Lingkungan kerja adalah lingkungan tempat di mana karyawan itu bekerja, lingkungan kerja yang baik dapat meningkatkan kinerja karyawan, sebaliknya lingkungan kerja yang kurang baik dapat menurunkan kinerja karyawan. Hal ini menunjukan bahwa lingkungan kerja internal yang meliputi penerangan yang kurang baik, suhu ruangan yang terlalu panas atau terlalu dingin, serta suara bising yang mengganggu, penggunaan warna ruangan yang tidak sesuai, ruang kerja yang terlalu sempit dan keamanan kerja yang kurang memadai dapat mengganggu karyawan dalam bekerja dan akhirnya dapat menurunkan motivasi serta tingkat kepuasan kerja karyawan itu sendiri. Menurut Nitisemito (2000:183)“ Lingkungan kerja adalah segala sesuatu yang ada di sekitar para pekerja yang dapat mempengaruhi dirinya dalam menjalankan tugas-tugas yang diembankan".

Menurut As'ad (2004) kepuasan kerja adalah perasaan seseorang terhadap pekerjaannya. Ini berarti bahwa konsepsi kepuasan kerja semacam ini melihat kepuasan kerja itu sebagai hasil interaksi manusia dengan lingkungannya. Dalam organisasi pemerintahan pegawai harus dihargai harkat dan martabatnya sebagai manusia seutuhnya. Perasaan-perasaan pegawai menyangkut pekerjaannya harus mendapat perhatian yang serius dari para pimpinan organisasi, dan pegawai juga perlu mendapat umpan balik tentang kerja mereka. Hasil penilaian kinerja dapat membantu pimpinan dalam menentukan sikap pegawainya terhadap kondisi organisasi, bagaimana sikapnya terhadap tantangan-tantangan, pertumbuhan dan keanekaragaman yang ada dalam organisasi dan menentukan kemampuan pegawai itu sendiri. Perubahan-perubahan sikap pegawai merupakan tanda adanya perubahan-perubahan dalam kepuasan kerja. Kepuasan kerja bagi pegawai merupakan suatu hal yang sangat penting karena pegawai yang benar-benar puas dalam bekerja akan benar-benar bahagia, sehingga akan membawa dampak dalam memotivasi kerja selanjutnya dan pegawai akan dapat memberikan layanan yang baik kepada pelanggan.

Dari beberapa penjelasan di atas maka penelitian ini akan dilaksanakan dengan judul

"Pengaruh Budaya Organisasi, Lingkungan Kerja, Terhadap Kinerja Dosen, dan Kepuasan Kerja Sebagai Variabel Intervening Pada Universitas Satya Negara Indonesia (USNI)".

\section{Tinjauan Pustaka (Literature Review)}

Kinerja adalah nilai dari seperangkat perilaku karyawan yang berkontribusi, baik secara positif atau negative terhadap pemenuhan tujuan organisasi. Kinerja ditentukan oleh tiga factor, yaitu 1) kinerja tugas (task force) dipengaruhi oleh rutinitas dan adaptasi, 2) perilaku kesetiaan atau komitmen (citizenship behavior) dipengaruhi oleh factor interpersonal dan organisasional termasuk imbalan, 3) perilaku produktif tandingan (counter productive behavior) dipengaruhi oleh factor deviasi sifat, factor deviasi produksi, factor deviasi politik, dan factor agresi personal termasuk kepuasan. Tingkat keberhasilan seseorang dalam menyelesaikan pekerjaannya disebut dengan istilah level of performance atau level kinerja. 
Budaya organisasi adalah sistem nilai yang diyakini dan dapat dipelajari dapat di terapkan dan di kembangkan secara terus-menerus. Budaya organisasi juga berfungsi sebagai perekat, pemersatu, identitas, citra, brand, pemicu-pemicu (motivator) pengembangan yang berbeda dengan organisasi lain yang dapat dipelajari dan diwariskan kepada generasi berikutnya dan dapat dijadikan acuan perilaku manusia dalam organisasi yang berorientasi pada budaya.

organisasi adalah sistem makna dan keyakinan bersama yang dianut oleh para anggota organisasi yang menentukan, sebagian besar bagaiamana para karyawan bersikap. Budaya organisasi dapat dibentuk dengan tujuh dimensi, yaitu Inonovation and risk taking (inovasi dan pengambilan resiko), Attention to detail (perhatian lebih detail), Outcome orientation (orintesi hasil), People orientation (orientasi pada manusia), Team orientation (orientasi tim), Aggressiveness (agresivitas), dan Stability (stabilitas),

Disamping itu budaya organisasi sangat penting bagi kehidupan seseorang dalam bekerja. Budaya Organissi dalam artian ini merupakan kebiasaan dalam berorganisasi sebagai sarana untuk mencapai tujuan organisasi. Berbagai aspek budaya orgnisasi yang terdapat di dalam suatu organisasi dan apabila dapat dilaksanakan dengan baik akan mendatangkan kepuasan kerja bagi pegawai tersebut, yakni suatu perasaan menyenangkan yang muncul sebagai akibat dari kebiasaan hidup dalam beroroganisasi atau dalam melaksanakan pekerjaan. Dengan demikian dapat diduga bahwa budaya organisasi berpengaruh langsung terhadap kepuasaan kerja pegawai.

Lingkungan kerja merupakan segala sesuatu yang ada di sekitar karyawan pada saat bekerja, baik yang berbentuk fisik ataupun non fisik, langsung atau tidak langsung, yang dapat mempengaruhi dirinya dan pekerjaanya saat bekerja. Lingkungan kerja meliputi ruang, udara, suhu, cahaya, kebisingan, alat-alat, bahan-bahan, tata letak fisik, dan hubungan rekan kerja serta kualitas dari semuanya mempunyai dampak positif terhadap kinerja pegawai, artinya jika keseluruhan sarana dan prasarana yang ada di sekitar karyawan yang sedang melakukan pekerjaan itu sendiri kondusif maka kinerja karyawan akan meningkat. Dengan demikian, dapat diduga bahwa lingkungan kerja memiliki pengaruh langsung terhadap kinerja pegawai.

Di samping itu lingkungan kerja juga merupakan salah satu factor yang berperan penting dan strategis dalam kelangsungan hidup suatu perusahaan. Lingkungan kerja dapat mendorong semangat kerja pegawai dan sekaligus membuat kepuasan kerja pegawai meningkat sehingga tujuan perusahaan dapat tercapai secara efektif dan efisien. Oleh sebab itu lingkungan kerja suatu organisasi perusahaan dituntut untuk selalu kondusif yang mampu memuaskan pegawai dalam bekerja sehingga diperoleh karyawan yang tidak hanya mampu bekerja akan tetapi juga bersedia bekerja ke arah pencapaian tujuan perusahaan. Dengan demikian, dapat diduga bahwa lingkungan kerja memiliki pengaruh langsung terhadap kepuasan kerja.

Kepuasan kerja adalah sebagai keadaan emosi yang positif dari mengevaluasi pengalaman kerja seseorang. Beberapa hal-hal utama yang mempengaruhi kepuasan kerja bisa dikelompokkan mejadi tiga. Pertama, faktor organisasi yang teridir atas gaji (imbalan), kesempatan untuk promosi, pekerjaan itu sendiri, kondisi kerja (lingkungan kerja), dan prosedur organisasi. Kedua, faktor kelompok yang teridiri atas atasan (supervisor, pimpinan, manajer) dan rekan kerja. Ketiga, faktor individu yang terdiri atas kebutuhan-kebutuhan pribadi dan aspirasinya.

Dalam bekerja seseorang membutuhkan perasaan menyenangkan, terutama yang muncul dari penilaian kerja atau pengalaman kerja yang terkait dengan pekerjaan itu sendiri, Perasaan menyenangkan tersebut akan membuat seseorang tenang dan nyaman dalam bekerja, sehingga memungkinkan dirinya bekerja dengan loyal, handal, cakap dalam komunikasi, terampil secara interpersonal dan kaya inisiatif. Kepuasan kerja karyawan merupakan hal yang bersifat individual tentang perasaan seseorang terhadap pekerjaannya. Kepuasan kerja merupakan salah satu faktor yang dapat mempengaruhi kinerja. Semua ini diperlukan untuk membangun kinerja sebagai cerminan hasil kerja yang unggul yang dicapai melalui serangkaian kegiatan yang dilaksanakan secara efisien dan efektif dalam rangka mencapai tujuan organisasi. Dalam tataran ini terlihat 
bahwa kepuasan kerja diperlukan untuk membangun kinerja. Dengan demikian, dapat diduga bahwa kepuasan kerja memiliki pengaruh langsung terhadap kinerja pegawai.

\section{Metodologi Penelitian (Research Methodology)}

Penelitian ini bertujuan untuk menganalisis pengaruh langsung budaya organisasi terhadap kinerja pegawai, lingkungan kerja terhadap kinerja pegawai, budaya organisasi terhadap kepuasan kerja, lingkungan kerja terhadap kepuasan kerja, dan kepuasan kerja terhadap kinerja pegawai.

Tempat penelitian ini dilaksanakan di Universitas Satya Negara Indonesia (USNI). Waktu penelitan ini dilaksanakan bulan September 2014 sampai dengan bulan Juni 2015 selama enam bulan. Metode penelitian yang digunakan dalam penelitian ini adalah metode penelitian deskriptif dengan survey dengan menggunakan instrument kuesioner. Sesuai metodologi penelitian yang digunakan dalam penelitian ini, maka teknik analisis datanya adalah analisis jalur (path analysis).

Populasi dalam penelitian ini adalah seluruh Dosen Tetap USNI sebanyak 50 orang. Sedangkan yang menjadi sampel dalam penelitian ini adalah seluruh jumlah populasi atau menggunakan metode sensus yaitu 50 orang. Hal ini dilakukan karena jumlah dosen tetapnya di bawah 100 sehingga supaya hasilnya memuaskan maka semua populasi dibuat menjadi sampel.

\section{Hasil Penelitian dan Pembahasan (Results and Analysis)}

\section{Uji Instrument}

Dari hasil uji validitas menunjukkan bahwa instrument dari semua variabel adalah valid ( $\mathrm{r}_{\text {hitung }}>$ $\mathrm{r}_{\text {tabel}}$ ), artinya semua instrument dapat digunakan dalam penelitian ini. Sedangkan hasil uji reliabilitas menunjukkan bahwa instrument dari semua variabel adalah reliable (Combrach $\alpha>$ $0,7)$, artinya semua instrument dari semua variabel adalah handal untuk digunakan dalam penelitian ini.

\section{Classic Asunmption Test}

Dari hasil Uji normal probability plot (P-Plot), yaitu menggambarkan data sesungguhnya membentang mengikuti sumbu diagonal, maka dapat disimpulkan bahwa data variabel Kinerja Pegawai (Y), Budya Organisasi $\left(\mathrm{X}_{1}\right)$, Lingkungan Kerja $\left(\mathrm{X}_{2}\right)$, dan Motivasi Kerja $(\mathrm{Z})$ tersebar secara normal.

Dari hasil Uji Heterokedastisitas data variabel Kinerja Pegawai (Y), Budya Organisasi $\left(\mathrm{X}_{1}\right)$, Lingkungan Kerja $\left(\mathrm{X}_{2}\right)$, dan Motivasi Kerja $(\mathrm{Z})$ menunjukkan bahwa penyebaran nlai-nilai residual tidak membentuk suatu pola tertentu yang berarti bahwa varians variabel bersifat konstan atau tidak terjadi heterokedastisitas.

\section{Path Analysis}

\section{Pengaruh Langsung Positif Budaya Organisasi $\left(X_{1}\right)$ terhadap Kinerja Karyawan (Y)}

Untuk membuktikan Hipotesis bahwa Budaya Organisasi $\left(\mathrm{X}_{1}\right)$ berpengaruh langsung terhadap Kinerja Dosen (Y). dengan menggunakan analisis jalur diperoleh koefisien jalur $\mathrm{P}_{\mathrm{y} 1}$ sebesar -0,007 dengan p-value $=0,970 / 2=0,485>0,05$ maka $\mathrm{H}_{0}$ diterima, yang berarti Budaya Organisasi tidak berpengaruh terhadap Kinerja Dosen. 
Hasil penelitian ini menyimpulkan bahwa budaya organissi tidak berpengaruh langsung positif terhadap Kinerja Dosen, dengan demikian implikasinya adalah bahwa dalam meningkatkan Kinerja Dosen perlu memperhatikan budaya organisasi yang semakin meningkat. Budaya Organisasi yang harus diperhatikan, antara lain terutama budaya organisasi yang berorientasi orang dan berorientasi tim,

\section{Pengaruh Langsung Positif Lingkungan Kerja $\left(\mathrm{X}_{2}\right)$ terhadap Kinerja Pegawai $(\mathrm{Y})$}

Untuk membuktikan Hipotesis bahwa Lingkungan Kerja $\left(\mathrm{X}_{2}\right)$ berpengaruh langsung positif terhadap Kinerja Dosen (Y), dengan menggunakan analisis jalur diperoleh koefisien jalur $\mathrm{P}_{\mathrm{y} 2}=0,597 ; \mathrm{t}_{0}=2,829, \mathrm{p}$-value $=0,059 / 2=0,0295<0,05, \mathrm{H}_{0}$ ditolak, yang berarti Lingkungan Kerja $\left(\mathrm{X}_{2}\right)$ berpengaruh langsung positif terhadap Kinerja Dosen (Y).

Hasil penelitian ini menyimpulkan bahwa Lingkungan Kerja berpengaruh langsung positif terhadap Kinerja Dosen, dengan demikian implikasinya adalah bahwa dalam meningkatkan Kinerja Dosen perlu ditingkatkan kualitas lingkungan kerja. Peningkatan kualitas lingkungan kerja dapat dilakukan dengan meningkatkan kualitas lampu penerangan ruang kerja, membuat suhu ruang kerja yang sejuk. Sirkulasi udara yang bagus, terhindar dari suara bising, membuat warna ruangan yang terang, dan membuat fasilitas ruang kuliah yang semakin berkualitas dan fasilitas praktikum. Dengan dilaksakannya lingkungannya kerja yang semakin berkualitas ini maka akan dapat meningkatkan Kinerja Dosen Universitas Satya Negara Indonesia (USNI).

\section{Pengaruh Langsung Positif Kepuasan Kerja (Z) terhadap Kinerja Pegawai (Y)}

Untuk membuktikan Hipotesis bahwa Kepuasan Kerja (Z) berpengaruh langsung terhadap Kinerja Dosen (Y). dengan menggunakan analisis jalur diperoleh koefisien jalur $\mathrm{P}_{\mathrm{yZ}}$ $=-0,142 ; \mathrm{p}$-value $=0,433 / 2=0,2165>0,05, \mathrm{H}_{0}$ diterima, yang berarti Kepuasan Kerja $(\mathrm{Z})$ tidak berpengaruh terhadap Kinerja Dosen (Y).

Hasil penelitian ini menyimpulkan bahwa Kepuasan Kerja tidak berpengaruh langsung positif terhadap Kinerja Dosen, dengan demikian implikasinya adalah untuk meningkatkan Kinerja Dosen maka perlu ditingkatkan kepuasan kerja dosen, dengan memperhatikan berbagai aspek yang berhubungan dengan kehidupan dosen dalam berorganisasi atau bekerja, yaitu memperbaiki tingkat gaji, memberikan kesempatan untuk dipromosikan, memiliki pemimpin yang jujur, cerdas, adil, dan sebagainya. Memiliki rekan kerja yang saling pengertian dan rasa empati yang tinggi, termasuk juga beban kerja dosenj itu sendiri yang tidak terlalu berat dan tidak terlalu sulit. Dengan memperhatikan atau bahkan meningkatkan berbagai hal yang berhubungan dengan kepuasan kerja dosen maka akan dapat meningkatkan kinerja dosen Universitas Satya Negara Indonesia (USNI).

\section{Pengaruh Langsung Positif Budaya Organisasi $\left(X_{1}\right)$ terhadap Kepuasan Kerja $(Z)$}

Untuk membuktikan Hipotesis bahwa Budaya Organisasi $\left(\mathrm{X}_{1}\right)$ berpengaruh langsung terhadap Kepuasan Kerja $\left(\mathrm{X}_{3}\right)$. dengan menggunakan analisis jalur diperoleh koefisien jalur $\mathrm{P}_{\mathrm{Z1}}=0,220, \mathrm{p}$-value $=0,157 / 2=0,78>0,05$, atau $\mathrm{H}_{0}$ diterima, yang berarti tidak terdapat pengaruh Budaya Organisasi $\left(\mathrm{X}_{1}\right)$ terhadap Kepuasan Kerja $(\mathrm{Z})$

Hasil penelitian ini menyimpulkan bahwa budaya organisasi tidak berpengaruh langsung positif terhadap Kepuasan Kerja, dengan demikian implikasinya adalah untuk meningkatkan Kepuasan Kerja Dosen maka perlu dilakukan perbaikan budaya organisasi yang dapat meningkatkan ketengnangan dan kesenangan kerja para dosen sehingga dia mera puas dalam bekerja. Berbagai cara yang dapat dilakukan untuk meningkatkan ketengan dan 
kesenangan dosen, yaitu dengan meningkatkan budaya organsasi yang berorientasi pada orang dan berorientasi pada tim.

\section{Pengaruh Langsung Positif Lingkungan Kerja $\left(X_{2}\right)$ terhadap Kepuasan Kerja $(Z)$}

Untuk membuktikan Hipotesis bahwa Lingkungan Kerja $\left(\mathrm{X}_{2}\right)$ berpengaruh langsung terhadap Kepuasan Kerja (Z). dengan menggunakan analisis jalur diperoleh koefisien jalur $\mathrm{P}_{\mathrm{Z} 2}=0,526 ; \mathrm{p}$-value $=0,001 / 2=0,0005<0,05$, atau $\mathrm{H}_{0}$ ditolak, yang berarti Lingkungan Kerja $\left(\mathrm{X}_{2}\right)$ mempunyai pengaruh langsung positif terhadap Kepuasan Kerja $(\mathrm{Z})$.

Hasil penelitian ini menyimpulkan bahwa Lingkungan Kerja berpengaruh langsung positif terhadap Kepuasan Kerja, dengan demikian implikasinya adalah bahwa dalam meningkatkan Kinerja Dosen perlu ditingkatkan kualitas lingkungan kerja, yaitu berupa peningkatkan kualitas lampu penerangan ruang kerja, membuat suhu ruang kerja yang sejuk. sirkulasi udara yang bagus, terhindar dari suara bising, membuat warna ruangan yang terang, dan meningkatkan kualitas fasilitas proses belajar mengajar, misalnya ruanga praktikum, fasilitas internet yang memadai, dansebagainya. Dengan dilaksakannya lingkungannya kerja yang semakin berkualitas ini maka akan dapat meningkatkan Kepuasan Kerja Dosen Universitas Satya Negara Indonesia (USNI).

\section{Kesimpulan}

1. Budaya organisasi berpengaruh tidak signifikan terhadap kinerja dosen tetap di USNI, artinnya tidak terdapat pengaruh langsung positif antar budaya organisasi dengan kinerja dosen tetap USNI.

2. Lingkungan kerja berpengaruh signifikan terhadap kinerja dosen tetap di USNI, artinnya terdapat pengaruh langsung positif antara lingkungan kerja dengan kinerja dosen tetap USNI.

3. Budaya organisasi berpengaruh tidak signifikan terhadap kepuasan kerja dosen tetap di USNI, artinnya tidak terdapat pengaruh langsung positif antara budaya organisasi dengan kepuasan kerja dosen tetap USNI.

4. Lingkungan kerja berpengaruh signifikan terhadap kepuasan kerja dosen tetap di USNI, artinnya terdapat pengaruh langsung positif antara lingkungan kerja dengan kepuasan kerja dosen tetap USNI.

5. Kepuasan kerja berpengaruh tidak signifikan terhadap kinerja dosen tetap di USNI, artinnya tidak terdapat pengaruh langsung positif antara kepuasan kerja dengan kinerja dosen tetap USNI.

\section{Saran}

Berdasarkan hasil pengujian terhadap variabel budaya organisasi, lingkungan kerja, kepuasan kerja, dan kinerja pegawai maka implikasi yang disarankan dalam penelitian ini antara lain:

1. Variabel budaya organisasi dalam penelitian ini berpengaruh tidak signifikan terhadap kinerja dosen, maka disarankan agar pihak manajemen menciptakan buadaya orgasniasi yang semakin kondusif, misalnya membuat kebijakan, menjalankan kebijakan-kebijakan dengan pasti, dan sebagainya.

2. Variabel lingkungan keja dalam penelitian ini berpengaruh signifikan terhadap kinerja dosen, maka disarankan agar pihak manajemen meningkatkan lingkungan kerja agar semakin kondusif, seperti meningkatkan fasilitas proses belajar mengajar.

3. Variabel kepuasan kerja dalam penelitian ini berpengaruh tidak signifikan terhadap kinerja dosen, maka disarankan agar pihak manajemen meningkatkan factor-faktor yang mempengaruhi kepuasan kerja dosen, seperti peningkatan insentif material dan non material. 


\section{DAFTAR PUSTAKA}

Akdon, Cara Menggunakan dan Memakai Path Analysis (Analisis Jalur) Bandung: Alfabeta,2012 As'ad, Psikologi Industri, Edisi Keempat, Yogyakarta: Liberty, 2004.

Collquitt, Jason A. Jeffery A. LePine \& Michael J. Wesson, Organizational Behviour; Improving Performance and zcommitment in the Workplace, New York: MCGraw-Hill, 2009.

Chaterina Melina Taurisa dan Intan Parimita, Analisis Pengaruh BudayaOrganisasi dan Kepuasan Kerja Terhadap Komitmen Organisasional Dalam Meningkatkan Kinerja Karyawan (studi pada PT. Sido Muncul Kaligawe Semarang). Jurnal Bisnis dan Ekonomi (JBE), ISSN: 1412-3126 2012.

Daft Richard L., Management, Penerjemah Edward Tanujaya, Jakarta: Salemba Empat, 2006, h.125.

Flippo Edwin B., Manajemen Personalia, Edisi Keenam Jilid 2, Terjemhan Moh. Masud, Jakarta: Erlangga, 1992, h.110.

Ghozali, Imam, Aplikasi Analisis Multivariate dengan Program IBM SPSS 19. Semarang: Badan Penerbit Universitas Diponegoro, 2011.

Jackson, Schuler, dan Werner, Pengelolaan Sumber Daya Manusia, Buku 1 Edisi Kesepuluh, Penerjemah Benny Prihartanto, Jakarta: Salemba Empat, 2010.

Jennifer M. George \& Haren R. Jonnes, Understanding and Manging Organizational Behaviour, $4^{\text {th }}$ Edition, New Jersey: Pearson Prentice Hall, 2005.

Kusuma Ali, Pengaruh Lingkungan Kerja, Motivasi, dan Budaya Organisasi terhadap Kepuasan Serta Dampaknya terhadap Kinerja Pegawai. Jurnal Bisnis dan Manajemen Voll, No.4 Desember 2007.

Luthans, Fred. Organizational Behaviour, $11^{\text {th }}$ Edition, Singapore McGraw-Hill International Adition, 2008.

Luthans \& Doh, International Managament Culture, Strategy, and Behaviour, $7^{\text {th }}$ Edition, New Yoek: McGraw-Hill, 2009.

Mondy R. Wayne, Manajemen Sumber Daya Mnusia, Edisi 10Jilid 2, Alih Bahasa Bayu Airlangga, Jakarta: Eralangga, 2008.

Nelson, Debra L.\& Jame Campbell Quick, Organizational Behaviour, South Western: Thomson, 2006.

Nitisetimo Alex S. Manjemen Personalia: Manajemen Sumberdaya Manusia, Ed.3., Jakarta: Ghalia Indonesia, 2000.

Ojo, Olu, "Impact Assessment of Corporate Culture on Employee Job Performance," Business Intelligence Journal, Vol. 2, Agustus 2009.

Robbin Stephen P., Perilaku Organisasi, Alih Bahasa Handyana Pujaatmaka, Jakarta: Prenhallindo, 1996.

Robbin Stephen P. dan Mary Coulter, Manajemen, Edisi Kedelapan, Jakarta: Indeks, 2007.

Robbins Stephen and Mary Coultert, Managament, New Jersey, Pearson Education, Inc. $10^{\text {th }}$ Edition, 2010.

Robert Kreitner and Angelo Kinick, Organization Behaviour, Seventh Editon, New York: Mc.Graw-Hill, 2007.

Schuler Randall S. dan Susan E.Jackson, Manajemen Sumber Daya Manusia Menghadapi Abad ke 21, Alih Bahasa Nurdin Sobari, Jakarta: Erlangga, 1997.

Sianipar J.P., Perencanaan Peningkatan Kinerja, Bahan Diklat Spama, Jakarta, Lembaga Administrasi Negara (LAN), 1999.

Sinambela, Lijan Poltak, Kinerja Pegawai Teori Pengukuran dan Implikasi. Yogyakarta: Graha Ilmu, 2012.

Sugiyono, Metode Penelitian Kuantitatif Kualitatif dan R\&D, Bandung: Alfabeta, 2012. 
Sutanto, Aftoni, 2002, Peran Budaya Organisasiuntuk Meningkatkan Kepuasan Kerja dan Kinerja Karyawan, Benefit, Vol. 6 No. 2. Juni 2002.

Swatno H. dan Donni Juni Priansa, Manajemen SDM dalam Organisasi Politik dan Bisnis, Bandung: Alfabeta, 2011.

Syahbudin, Pengaruh Budaya Organisasi, motivasi, dan Kepuasan Kerja terhadap Kinerja, Disertasi Program Pasca Sarjana Doktoral Universitas Negeri Jakarta, 2012.

Umam, Khaerul, Perilaku Organisasi, Cetakan Pertama, Bandung: CV. Pustaka Setia, 2010.

Umar, Husein, Desain Penelitian dan Perilaku Karyawan, Jakarta: PT. Raja Grafindo Persada, 2010.

Wibowo, Budaya Organisasi, Jakarta: Rajawali Pers, 2010. 